Мешкова Людмила Игоревна

старший лаборант с высшим образованием отдела социологии образования

Института социологии Российской академии наук

\section{ТРАНСФОРМАЦИЯ ПРОЦЕССА СОЦИАЛИЗАЦИИ. МЕХАНИЗМЫ ПРИНЯТИЯ РЕШЕНИЯ О ВЫБОРЕ ОБРАЗОВАТЕЛЬНОЙ И ПРОФЕССИОНАЛЬНОЙ ТРАЕКТОРИИ [1]}

\section{Аннотация:}

В статье рассматриваются возможности применения социологических теорий в исследовании о трансформации современных агентов социализации и предполагаемом влиянии этих изменений на формирование решения индивида о выборе образовательной и профессиональной траектории. Анализируются различные аспекты тематики и возможности интерпретации данных с помощью основных социологических подходов, разработанныХ в конце XIX - начале XX в. Приводятся эмпирические примеры в качестве возможных иллюстраций работы рассматриваемых теорий. Делается вывод о необходимости построения комплексной концептуальной платформы исследования $в$ связи с особенностями современного процесса социализации и его возможным воздействием на профессиональный выбор подростка.

\section{Ключевые слова:}

социализация, образовательные и профессиональные траектории, социальная система, индивид, социальные факторы, агенты социализации, механизмы социализации, теории социализации выбор специальности.
Meshkova Lyudmila Igorevna

Senior Laboratory Assistant, Sociology of Education Department, Institute of Sociology, Russian Academy of Sciences

\section{TRANSFORMATION OF SOCIALIZATION PROCESS. MECHANISMS OF MAKING DECISIONS ON EDUCATIONAL AND CAREER PATH [1]}

Summary:

The article discusses resources of sociological theories in the study of the transformation of modern agents of socialization and expected impact of these changes on the creation of an individual choice of educational and career path. The author analyses various aspects of the subject matter and the possibility of interpreting the data in the framework of the basic sociological approaches developed at the late XIX - early XX centuries. Empirical examples as possible demonstration of the theories operation are provided. It is concluded that there is need for a comprehensive conceptual framework of research taking into account peculiarities of the modern process of socialization and its possible impact on the career choice made by a teenager.

Keywords: socialization, educational and professional paths, social system, individual, social factors, socialization agents, mechanisms of socialization, theories of socialization, major choice.

Социализация как один из базовых социальных процессов существует с давних времен и развивается вместе с обществом. Это развитие может заключаться в изменениях самих агентов социализации и социальных факторов (смена патриархальной семьи на нуклеарную, появление новых технологий для общения и распространения информации), а также механизмов их работы (смена позиций в балансе авторитетов индивида, таких как уход семьи на второй план и т. п.). Сегодня мы сталкиваемся с последствиями этих трансформаций, которые в связи с событиями второй половины XX и начала XXI в. оказались достаточно динамичными и серьезными. Глобализация, технический прогресс, различные социальные и политические перемены, такие как распад СССР и изменения в экономике страны, - все это могло привести к тому, что одни агенты социализации терпят кризис и уступают место другим, а третьи, трансформируясь в результате социальных и экономических изменений, обретают бо̀льшую силу воздействия на индивида, нежели имели раньше.

Изменения в экономике и занятости населения по отраслям, которые произошли за последние десятилетия, можно увидеть на примере проведенных исследований [2, с. 51]. По данным рисунка 1, с 1987 по 2004 г., во-первых, случились сдвиги в распределении занятых людей в возрасте до 30 лет по сферам работы, во-вторых, появились новые отрасли. Отмечая перемены в распределении занятости, делаем вывод о том, что перемены также происходят и в образовательной сфере. А значит, эти изменения вызваны в свою очередь другими факторами.

Современное молодое поколение оказывается социальной группой, чьи отношения с социальной реальностью выстраиваются иначе, нежели у предыдущих поколений. В связи с этим представляется правомерной гипотеза о том, что в механизмах социализации происходят некие изменения, которые как в целом сказываются на формировании социального «я» подростка, так и оказывают воздействие на его жизненные решения и выборы, а именно на образовательные и профессиональные траектории. Например, специальности и профессии, которые выбирают молодые люди, 
далеко не всегда оказываются результатом семейной преемственности, выбора родителей или школьного воспитания. Данную тенденцию также можно проследить в эмпирических исследованиях.

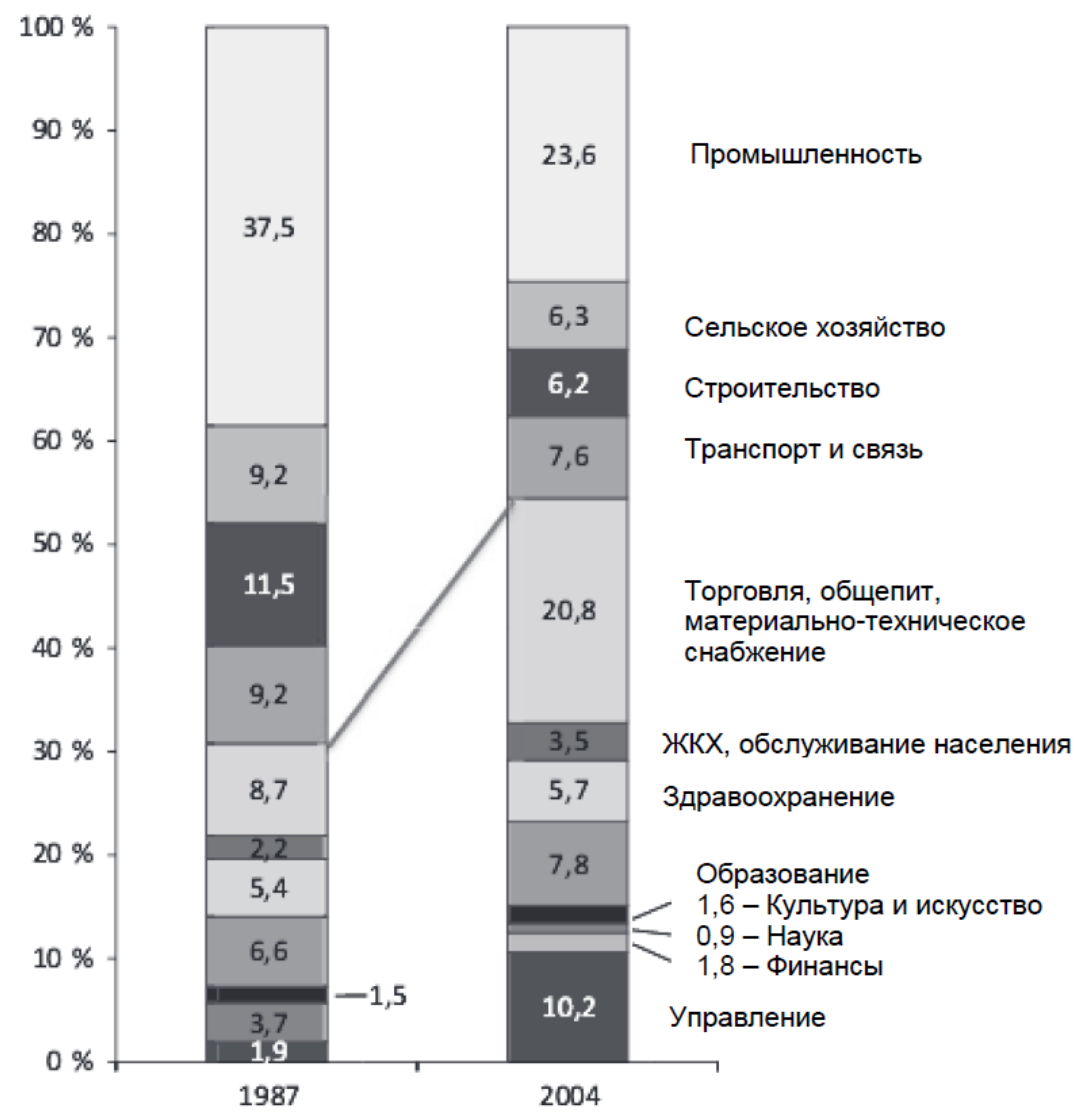

Рисунок 1 - Распределение занятых в возрасте до 30 лет по основным отраслям экономики в 1987 и 2004 гг., РФ, \%

На рисунке 2 приведены результаты опроса 2014 г., проведенного в рамках исследования Российского научного фронда «Образование, рынок труда и социальное поведение молодежи в современной экономической ситуации». Хотя действия «традиционных» агентов социализации (советы родителей и их пример, жизненный опыт более взрослых знакомых) остаются для учащихся 11-х классов наиболее значимыми при выборе будущей специальности (в инструментальном смысле - наиболее часто указываемыми в анкете), Интернет и СМИ также оказывают заметное воздействие на процесс профессионального самоопределения (информация, поступающая из этих источников, занимает третье место по упоминаемости респондентами после указанных выше). Обнаруживается немалое влияние друзей и сверстников (четвертое место), в то время как работники учебного заведения, куда подросток хочет поступить, и преподаватели школы реже указывались учащимися в качестве повлиявших на выбор пути после школы (пятое и шестое места соответственно).

Говоря об агентах социализации и социальных факторах, необходимо провести важное различение. Исходя из общего социологического определения фрактора как «причины, движущей силы какого-либо явления, процесса, определяющего его характер или отдельные его черты» (Российская социологическая энциклопедия, 1998), в данном случае понимаем под социальными факторами различные влияния социальной среды, идущие от социальных институтов и организаций. Что касается агентов социализации, то это непосредственно сами «институты, люди и социальные группы, которые способствуют социализации личности» [3, с. 659], то есть персоналии и группы людей, с которыми индивид имеет дело в своей повседневной жизни. Это преподаватели со школы, друзья в социальных сетях, авторы передач, статей и книг, которые читает подросток, и т. п. То есть под факторами мы понимаем некие социальные силы и процессы, чье воздействие на индивида идет через агента социализации. Экономические, инфрормационные, культурные, технологические и другие процессы и явления реализуются в жизни человека через тех, с кем он взаимодействует, будь то родственники, друзья, авторы читаемых книг, статей, сообщений и «постов» в Интернете и просматриваемых телепередач. Такое различение представляется целесообразным для дальнейшего исследования, поскольку позволяет отделить социальных акторов от социальной среды. 


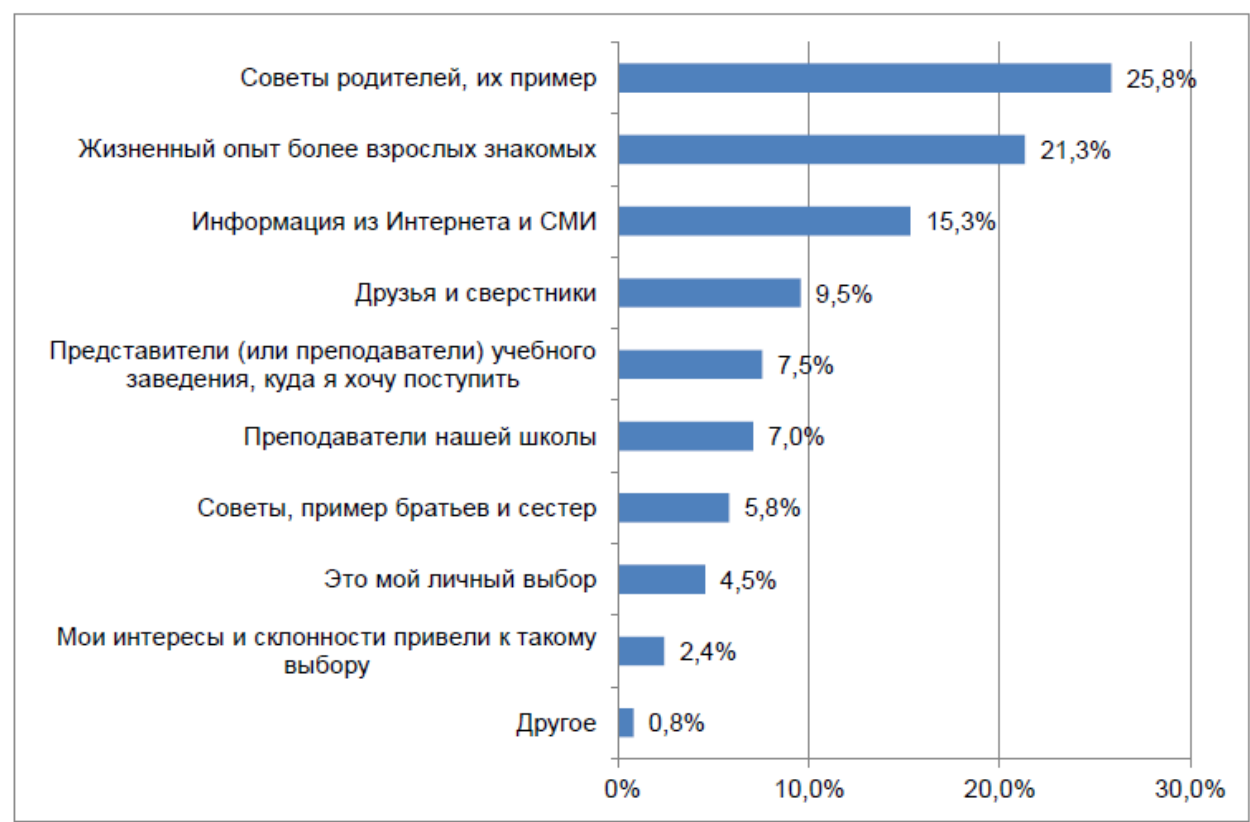

Рисунок 2 - Ответы 11-классников на вопрос:

«Что повлияло на Вас при выборе данной специальности (профессии)?», 2014 г.

Для проверки гипотезы о том, действительно ли происходят трансформации механизмов социализации и изменения баланса сил между агентами, необходимо провести работу с различными эмпирическими данными. Но прежде чем приступать к ней, нужно ответить на следующие исследовательские вопросы. Во-первых, как может быть понята трансформация механизмов социализации с концептуальной точки зрения и как меняется баланс сил агентов? Во-вторых, как именно действуют эти механизмы и как вследствие их работы происходит формирование выбора образовательных и профессиональных траекторий сегодня? И в-третьих, стоит направить исследовательский фокус на мотивы и причины выбора индивида, его видение и интерпретацию того, как он совершает выбор, или же на окружающие его различные воздействия и то, как они, сочетаясь между собой, определяют итоговое решение о выборе специальности.

Чтобы ответить на эти вопросы, необходимо выделить значимые аспекты описываемого процесса, понять, с помощью каких концептов они могут быть описаны, и, стало быть, сконструировать теоретическую базу для их изучения. Для этого обратимся к ряду теорий, разработанных представителями различных направлений социологической мысли конца XIX и XX в.

Важный вопрос, на который предстоит ответить в процессе анализа различных теорий и поиска основания для построения возможной концептуальной модели, заключается в том, какой исследовательский фокус выбрать. Следует акцентировать внимание на индивиде и том, как он постигает и воспроизводит воздействие агентов социализации и социальных факторов, на окружающей индивида социальной среде или на самих агентах и фракторах? Что станет оптимальной стратегией - акцент на одной из сторон изучаемой проблемы и ее глубинная проработка или же рассмотрение всех аспектов в комплексе с целью получить более полную картину? Для этого рассмотрим теории, которые сосредоточены в той или иной степени на описанных сторонах, и попробуем понять, какие понятия и концептуальные схемы могут быть применены непосредственно к изучению означенной проблемы.

Один из классиков социологической мысли, который заостряет внимание на индивиде в процессе социализации, - это Макс Вебер. Он называет социализацию адаптацией и описывает ее как двухсторонний процесс [4, с. 634]. По М. Веберу, включение индивида в общество происходит двойственным образом - индивид воспринимает, познает и переосмысливает существующие идеалы, ценности и нормы и впоследствии, следуя им, привносит также свои идеалы и ценности в производимые действия.

Такое понимание социализации позволяет рассматривать процесс выбора специальности подростком как стремление реализовать свою индивидуальность. Обращаясь к эмпирическим данным исследования «Образование, рынок труда и социальное поведение молодежи в современной экономической ситуации», отметим, что школьники и студенты вузов, отвечая на вопрос: «Чем Вас привлекает эта специальность или профессия?» - часто выбирали такие варианты ответов, как: «Эта специальность (профессия) мне интересна», «Полное совпадение моих способностей, наклонностей с характером выбранной специальности» и т. п. Используя возможность 
дать свой вариант ответа, они также писали, например: «Всегда хотел работать в этой области», «Желание с детства», «Личное мировоззрение и желание».

Другая важная часть теоретического наследия М. Вебера - анализ четырех типов действия индивида: традиционного, аффрективного, ценностно-рационального и целерационального позволяет выделить группы возможных причин, лежащих в основе выбора молодым человеком своей будущей специальности и учебного заведения [5, с. 627].

Традиционное действие работает, когда подросток руководствуется семейной или иной (например, национальной) традицией. (Сюда относятся, например, те, кто в ответах на вопрос: «Чем Вас привлекает эта специальность или профессия?» - отметили вариант: «Это семейная традиция».)

C аффрективным действием наиболее сходны ситуации, когда молодой человек принимает решение поступать в вуз лишь для того, чтобы стать обладателем диплома о высшем образовании (26,8 \% старшеклассников школ, отвечая на вопрос: «Почему Вы собираетесь продолжать учиться?» - отметили причину: "Надо получить “корочку”, без этого сегодня никуда» как очень важную и 36 \% - как важную). Сюда же относятся такие откровенные ответы респондентов (дописанные самостоятельно), как «Случайность», «Это был запасной вариант», «За компанию».

Ценностно-рациональное действие обнаруживает себя, когда молодой человек следует своим собственным сформировавшимся ценностям (например, многие в ответах на вопрос: «Чем Вас привлекает эта специальность или профессия?» - выбирали вариант: «Эта специальность (профрессия) мне интересна», а среди дописанных 11-классниками ответов встречаем: «Личный выбор», «Собственный взгляд на жизнь»); целерациональное - когда он или она преследуют конкретные цели (варианты ответов на вопрос: «Чем Вас привлекает эта специальность или профессия?» - «Эта специальность престижна», «Работа по этой специальности высоко оплачивается», «Работая по этой специальности, я смогу приносить пользу стране, обществу», «С этой специальностью можно сделать хорошую карьеру», «Востребована в наше время» и т. п.).

Впрочем, один и тот же вариант ответа может быть отнесен к разным типам действий. Так, например, ответ: «Надо получить “корочку”, без этого сегодня никуда» - подходит и к целерациональному действию, поскольку выпускник может вполне осознанно стремиться получить документ о высшем образовании, не собираясь строить свою дальнейшую карьеру в данной сфере.

Как уже было сказано, типы действий позволяют предположить, что может лежать в основе работы агентов социализации, то есть описать механизм воздействия семьи, преподавателей школы, информации из СМИ на профессиональный выбор молодого человека. С равной вероятностью все четыре типа могут определять их влияние. Например, авторы передач и статей СМИ могут формировать ценностно-рациональную ориентацию или мотивировать на получение специальности с конкретными целями, семья - склонять ребенка продолжать традицию или под сильным давлением авторитета поступать в вуз в «аффрективном» состоянии. Как было показано выше на примере с желанием получить «корочку», в основе выбора могут быть и более одного типа действия одновременно. Однако то, каковы типы действия, определяющие влияние конкретных агентов в разные временные периоды с разной частотой, может позволить понять, как предположительно трансформировались за последние годы механизмы социализации и как изменился баланс сил агентов.

Габриэль Тард определяет процесс социализации как подражание одного индивида другому. В основе этого подражания лежат «верования и желания». То есть человек, взаимодействуя с миром, воспринимает существующий порядок вещей, систему норм и ценностей и, подражая им, включается в социум [6, с. 63]. С точки зрения теории подражания подросток выбирает специальность, подражая агентам социализации, которые являются для него примером, на который он стремится быть похожим. Как показано на рисунке 2, школьники, отвечая на вопрос: «Что повлияло на Вас при выборе данной специальности (профессии)?» - нередко выбирали варианты: «Советы, пример братьев и сестер», «Жизненный опыт более взрослых знакомых». Как и в ответах родителей школьников на вопрос: «Что повлияло на решение о том, что будет делать Ваш ребенок после окончания школы?» - встречаются ответы: «Пример двоюродного брата», «Пример тети». Однако, помимо воздействия семьи, на профессиональный выбор респондентов влияют представители этой профессии. В то же время родители девятиклассников отметили, что на выбор подростков повлиял телеканал «Дискавери». Стало быть, происходит подражание как лично знакомым людям, которые являются для индивида авторитетами, так и тем, кто соответствующим образом преподносится средствами массовой информации. Теория Г. Тарда, по сравнению с типами действий М. Вебера, по-другому трактует механизмы воздействия агентов социализации на выбор подростка.

Исходя из высказанной в самом начале гипотезы и учитывая то, какие разные ответы дают респонденты, допускаем, что сегодня одни «примеры» для подражания сменяют или как минимум дополняются другими в формировании образовательных и профессиональных траекторий молодых людей. 
Георг Зиммель предлагает рассматривать социализацию как процесс обобществления индивида, т. е. как включение его в общество посредством процесса взаимодействия с окружающим миром. «Обобществление заключает его <индивида> в себе, и одновременно индивид противостоит обобществлению, индивид есть член организма обобществления и в то же время является замкнутым органическим целым, бытием для него и бытием для себя» [7, с. 521].

Общество по Г. Зиммелю - это совокупность форм взаимодействия индивидов и их групп. Следовательно, решение о выборе действия является одним из результатов взаимодействия подростка с другими людьми. Выше приведены примеры того, как в ответах респондентов на вопросы, касающиеся причин выбора специальности, встречаются варианты про общение со сверстниками, более старшими знакомыми и другими группами людей («общностями», по Г. Зиммелю). В этом смысле теория Г. Зиммеля может быть общим объяснением процесса фрормирования образовательной и профессиональной траектории, который является и частью, и результатом взаимодействия с окружающими людьми. Соответственно, в рамках гипотезы об изменениях механизмов социализации смена приоритетов в профессиях и специальностях может быть понята как реакция подростка на изменения окружающего мира. Появление социальных сетей как дополнительного пространства для общения и создания дружественных связей, рост получаемой информации через СМИ и Интернет могут приводить к формированию новых направлений в образовательных траекториях. Индивид реагирует на изменения вокруг себя. В сочетании с теорией подражания Г. Тарда концепция Г. Зиммеля также дает общее объяснение, почему подросток начинает подражать кому-то еще: он получает больший выбор примеров для подражания.

Прежде чем продолжить, попробуем обрисовать картину, которая начинает складываться при рассмотрении теорий на предмет их возможного применения для создания концептуальной базы исследования. Мы увидели, что теории М. Вебера, Г. Тарда и Г. Зиммеля получают своего рода «иллюстрации» в данных исследования РНФ. Респонденты давали ответы, которые могут быть интерпретированы с помощью теории о типах действий М. Вебера, теории подражания Г. Тарда и концепции обобществления Г. Зиммеля. Механизмами социализации, однако, скорее выступают теории подражания и обобществления, поскольку они объясняют, как индивид становится членом общества и формирует свое социальное поведение, а типы действий по М. Веберу скорее характеризуют следствия социализации, то есть чем индивид руководствуется, совершая свой выбор.

Также видим, что если рассуждать о рассматриваемых эмпирических примерах и теориях в рамках гипотезы, то получается, что сами принципы работы механизмов - «подражающий и пример для подражания», «общность людей и обобществляемый» - остаются неизменными в плане их социализирующих и влияющих на совершаемый выбор специальности функций. Однако их содержание, а именно элементы или составляющие, наполняющие механизмы, могут меняться в связи с изменениями социальной среды. То есть, следуя гипотезе, молодой человек ориентируется на другие примеры для подражания (друзья по социальным сетям, «герои» различных сюжетов, которые он черпает из СМИ и Интернета), входит в большее число общностей (интернет-круги по интересам, субкультуры), нежели несколько десятилетий назад. Могут изменяться и сами агенты в связи с прогрессом и социальным развитием: меняются школьные программы обучения и преподавательский подход, меняются сами семьи, например становясь нуклеарными, а не патриархальными. Соответственно, эти изменения могут приводить к гипотетическому изменению баланса сил агентов социализации. Чтобы понять, можно ли развить это понимание проблемы трансформации социализации и ее влияния на формирование образовательных и профрессиональных траекторий, продолжим рассмотрение теорий.

Джордж Герберт Мид в своих работах уделил социализации большое внимание. В его концепции "I, Ме" социализация предстает в нескольких аспектах. Это, во-первых, принятие роли, которое заключается в том, что индивид становится включенным в общество посредством осознания себя на месте другого индивида и разделения общей системы знаков, символов, жестов [8, с. 38]. Во-вторых, социализация по Миду - это формирование его Ме-составляющей, его понимания того, как он воспринимается другими людьми. Социализация делится на три этапа в соответствии с взрослением индивида - это Play (игра с самим собой, своего рода примерка различных ролей), Game (игра со сверстниками в спортивные и другие игры) и стадия организованной роли (итоговое формирование самости). Большое значение в социализации индивида и его повседневной жизни, по Дж.Г. Миду, также имеет генерализированный, или обобщенный, другой [9, с. 68]. Обобщенный другой - это группа индивидов, которая оказывает свое воздействие на Ме-составляющую личности и на которую личность ориентируется в своих решениях и жизненных выборах [10].

Применительно к исследованию того, как механизмы социализации могут влиять на образовательную и профессиональную траекторию, в теории Дж.Г. Мида особенно интересным представляется понятие обобщенного другого: это тот, на кого ориентируется подросток при выборе 
профессии. Это семья, более старшие знакомые, друзья и сверстники, некие иные референтные группы и персоны, представление о которых формируют СМИ и пр. Например, респонденты давали ответы, что на них повлияли представители выбранной профессии. Ролевой аспект социализации и концепция “І, Ме" также позволяют посмотреть на изучаемую проблему с той точки зрения, что выбор специальности - это принятие определенной роли на основе осознания того, как такая роль воспринимается значимым («обобщенным», по Дж.Г. Миду) окружением. Не случайно среди ответов на вопрос: «Чем Вас привлекает эта специальность или профессия?» - популярны варианты: «Эта специальность престижна» и подобные им, а среди дописанных 11-классниками собственных вариантов ответов на вопрос: «Что повлияло на Вас при выборе данной специальности (профессии)?» - встречаем, например: «Современное общество» и «Востребована в наше время».

Теория Дж.Г. Мида позволяет предположить, что если изменения в балансе сил агентов социализации действительно происходят, то они вызваны тем, что для молодых людей, помимо семьи, все чаще «обобщенными другими» становятся и иные люди и группы людей. Также в сочетании с теорией Г. Тарда данная концепция дает одно из возможных пониманий самих механизмов: подросток выбирает свою будущую специальность, подражая «генерализированному другому».

Представители феноменологической социологии делают акцент на других сторонах социализации индивида. Альфред Шюц описывает социализацию как усвоение индивидом обыденного, повседневного знания, которое несет для него практическую пользу. Окружающий мир, конструируемый и конституируемый индивидами, представляет собой интерсубъективную реальность, состоящую из обыденного знания, используемого индивидами в соответствии с принципом здравого смысла [11, с. 13]. Знание, выделяемое субъектом из повседневного мира, является нужным ему главным образом для осуществления своих целей и реализации потребностей. Индивид воспринимает прежде всего то, что ему действительно необходимо [12, с. 18].

Применяя теорию А. Шюца к исследуемой проблеме, можно предположить, что выбор образовательной и профессиональной траектории происходит на основе вывода индивида о практической пользе, которую несет для него определенная специальность. Вывод о пользе индивид делает на основе получаемой информации. Соответственно, принятие решения через понимание его практической пользы - это один из возможных механизмов действия агентов социализации и результат влияния социальных факторов.

Обращаясь к эмпирическим материалам, видим две группы ответов, которые могут быть интерпретированы с помощью подходов А. Шюца. С одной стороны, это степень важности, которую отмечали 11-классники в предлагаемых вариантах ответов на вопрос: «Почему Вы собираетесь продолжать учиться?». Причину: «Хочу стать компетентным работником» - 65 \% отметили как очень важную, а вариант: «Чтобы получить работу, соответствующую моим интересам и склонностям» - очень важным сочли 75 \%. Также среди дописываемых самостоятельно ответов студент, отвечая на вопрос: «Чем Вас привлекла эта специальность или профессия?» - написал: «Получение многосторонних знаний, которые пригодятся в жизни и развитии карьеры». Выпускники на вопрос: «Что повлияло на Вас при выборе данной специальности (профессии)?» - указали: «Мои способности».

С другой стороны, отвечая на вопрос: «Почему Вы собираетесь продолжать учиться?» школьники нередко отмечали важными такие варианты, как: «Чтобы легко найти работу в нашей стране», «Чтобы найти хорошо оплачиваемую работу», «Надо получить “корочку”, без этого сегодня никуда». Здесь же встречаем дописанный ответ: «Чтобы жить в достатке». Студенты вузов на вопрос: «Почему Вы решили учиться в вузе?» - отвечали: «Знания помогут в собственном деле», «Без образования на хорошую работу сложно попасть». Можно также предположить, что «обобщенный другой» (концепт, который может быть использован для возможного обозначения агентов социализации) становится для подростка таковым именно в связи с интересующей индивида пользой. Он ориентируется на персоны или группы людей, взаимодействие с которыми и ориентация на которых при принятии решения о выборе специальности, по его мнению, принесет пользу в будущем. То есть индивид прислушивается к мнению родителей или друзей, если понимает, что, например, предлагаемые ими варианты профессии прибыльны, востребованы или интересны для него.

Последователи А. Шюца Питер Бергер и Томас Лукман в работе «Конструирование социальной реальности» подробно анализируют понятие социализации. В их интерпретации это процесс восприятия индивидом объективизированной социальной реальности и его субъективизация в сознании личности, принятие внешнего мира или какой-то его части. Этот процесс динамичен и длится всю жизнь, «симметрия между объективной и субъективной реальностью никогда не бывает статичной, раз и навсегда установленной. Она всегда должна создаваться и воссоздаваться in actu. Иначе говоря, взаимосвязь между индивидуальным и объективным социальными мирами напоминает непрерывное балансирование» $[13$, с. 218]. 
Авторы выделяют три этапа в социализации личности. Это первичная социализация (индивид проходит ее в детстве и получает нормативные, ценностные и другие мировоззренческие и социальные основы) [14, с. 61], вторичная социализация (происходит на последующих этапах жизни индивида, таких как образование, поступление на работу) $[15$, с. 65] и поддержание и трансформация реальности (характеризуется тем, что индивид меняет свои социальные установки или все так же придерживается установок, обретенных на второй стадии) [16, с. 69].

Исследование того, как возможная трансформация социализации влияет на образовательные и профессиональные траектории, сосредоточено на подростках и молодых людях. В подходе П. Бергера и Т. Лукмана этой категории соответствует вторичная социализация, в ходе которой индивид формирует свое решение о выборе специальности. Интересным здесь представляется то, что на данном этапе подросток может делать выбор, ориентируясь на новые для него группы людей (в процессе первичной социализации превалирующее значение имеет семья, теперь же помимо нее возникают и другие агенты социализации, подсказывающие, как можно поступить). Соответственно, в рамках заявленной гипотезы можно предположить, что либо раньше в период вторичной социализации молодые люди уделяли им меньшее внимание, либо агенты социализации претерпевают изменения, которые ведут к тому, что их авторитет меняется для подростков: одни становятся более, а другие - менее значимыми. И то, что в этот период, как мы предполагаем, происходят данные изменения, ставит перед нами другие вопросы.

Рассмотренные теории дают возможное понимание механизмов действия агентов социализации, что в свою очередь позволяет создать концептуальную базу для изучения поведения подростка в вопросе формирования образовательных и профессиональных траекторий и того, как различные силы влияют на его выбор. Также мы видим, как уже было сказано выше, что если применять эти теории к гипотезе о трансформации социализации, то сами механизмы социализации остаются неизменными. И хотя еще нужно убедиться на эмпирическом материале, что изменения процесса социализации действительно происходят, уже можно сделать предположение о том, что меняется содержание элементов, составляющих эти механизмы (в плане изменения как количества референтных групп в жизни подростка, так и их сути), и вслед за изменением содержания меняется соотношение баланса сил агентов социализации. Тем не менее пока трудно понять, какой примерно может быть концептуальная модель для проведения исследования о возможной проблеме трансформации социализации и влияния этой трансформации на образовательные и профессиональные траектории. Ведь чтобы ее сконструировать, также необходимо осознавать, какие обстоятельства и фракторы, то есть воздействия социальной среды, могут вызывать эти трансформации и, что более важно, как можно объяснить эти воздействия в концептуальном плане. Для этого необходимо обратиться к теориям, чей фокус сосредоточен на социальной среде и обществе как единой системе, а также к работам, освещающим специфику современного общества.

\section{Ссылки и примечания:}

1. Статья подготовлена при поддержке Российского научного фонда (проект № 14-18-01985, «Образование, рынок труда и социальное поведение молодежи в современной экономической ситуации») в федеральном государственном бюджетном учреждении науки «Институт социологии РАН».

2. Новые смыслы в образовательных стратегиях молодежи: 50 лет исследования : монография / Д.Л. Константиновский, М.А. Абрамова, Е.Д. Вознесенская, Г.С. Гончарова, В.Г. Костюк, Е.С. Попова, Г.А. Чередниченко. М., 2015. 232 с.

3. Смелзер Н. Социология : пер. с англ. М., 1994. 688 с.

4. Вебер М. Избранные произведения. М., 1990. 808 с.

5. Там же. С. 627.

6. Тард Г. Законы подражания : пер. с фр. М., 2011. 304 с.

7. Зиммель Г. Избранное. Т. 2. Созерцание жизни. М., 1996

8. Мид Дж.Г. Избранное : сб. пер. / сост. и пер. В.Г. Николаев ; отв. ред. Д.В. Ефременко. М., 2009. 290 с.

9. Там же. С. 68.

10. Там же.

11. Шюц А. Избранное: Мир, светящийся смыслом : пер. с нем. и англ. М., 2004. 1056 с.

12. Там же. С. 18.

13. Бергер П., Лукман Т. Социальное конструирование реальности. Трактат по социологии знания. М., 1995.

14. Там же. С. 61.

15. Там же. С. 65.

16. Там же. С. 69.

\section{References:}

Berger, P \& Luckmann, T 1995, The social construction of reality. A treatise in the sociology of knowledge, Moscow, (in Russian).

Konstantinovsky, DL, Abramova, MA, Voznesenskaya, ED, Goncharova, GS, Kostyuk, VG, Popova, ES \& Cherednichenko, GA 2015, New meanings in the educational strategies of young people: 50 years of research, monograph, Moscow, 232 p., (in Russian). 
Mead, GH 2009, Nikolaev, VG (comp.) \& Efremenko, DV (ed.) 2009, Selected works, Moscow, 290 p., (in Russian). Schutz, A 2004, Selected works: The world having luminous meaning, Moscow, 1056 p., (in Russian).

Simmel, G 1996, Selected works, vol. 2. Contemplation of life, Moscow, (in Russian).

Smelzer, N 1994, Sociology, Moscow, 688 p., (in Russian).

Tard, G 2011, Laws of imitation, Moscow, 304 p., (in Russian).

Weber, M 1990, Selected works, Moscow, 808 p., (in Russian). 